\title{
Akreditasi Sekolah Menurut Persepsi Siswa : Studi di Sekolah Menengah Kejuruan (SMK) Negeri 1 Lubuk Sikaping
}

\author{
Eci Sarmila ${ }^{1}$, Nurhizrah Gistituati ${ }^{2}$ \\ ${ }^{1}$ Administrasi Pendidikan, Universitas Negeri Padang, ${ }^{2}$ Administrasi Pendidikan, Universitas Negeri Padang
}

Eci Sarmila1, e-mail: ukhteci.ap.unp@gmail.com

Nurhizrah Gistituati ${ }^{2}$, e-mail: gistituatinurhizrah@gmail.com

\begin{abstract}
This study aims to determine how appropriate the results of school accreditation are with the existing reality as seen from the students' perceptions. This type of research is descriptive quantitative. The population of this study were 480 class XI students at the Vocational High School (SMK) Negeri 1 Lubuk Sikaping, with a sample of 90 people who were determined using the Slovin formula. Sampling using proportional incidentil sampling technique. The research instrument used was a Likert Scale model questionnaire consisting of 36 items with alternative answers to Strongly Agree (SS), Agree (S), Disagree (KS), Disagree (TS), Strongly Disagree (STS). Before being used, the questionnaire is tested for validity and reliability first. The collected data is processed by looking for the average score and the average achievement level (TCR). The results showed that in general according to the accreditation students of Vocational High School (SMK) Negeri 1 Lubuk Sikaping, it was only in the appropriate criteria (not very suitable) between the rankings obtained and the existing reality, with a TCR of $81.18 \%$. However, if it is observed per the measured aspect, then there is one aspect, namely the facilities and infrastructure, the accreditation according to the students is not very suitable or does not match the rank obtained with the existing reality, with a TCR of 79.33 .
\end{abstract}

\begin{abstract}
Abstrak
Penelitian ini bertujuan untuk mengetahui seberapa sesuainya antara hasil akreditasi sekolah dengan kenyataan yang ada yang dilihat dari persepsi siswa. Jenis penelitian ini adalah deskriptif kuantitatif. Populasi penelitian ini adalah siswa kelas XI di Sekolah Menengah Kejuruan (SMK) Negeri 1 Lubuk Sikaping yang berjumlah 480, dengan besar sampel 90 orang yang ditentukan dengan menggunakan rumus Slovin. Pengambilan sampel menggunakan teknik proportional insidentil sampling. Instrumen penelitian yang digunakan berupa kuesioner model Skala Likert yang terdiri dari 36 item dengan alternatif jawaban Sangat Setuju (SS), Setuju (S), Kurang Setuju (KS), Tidak Setuju (TS), Sangat Tidak Setuju (STS). Sebelum digunakan, kuesioner tersebut diuji validitas dan reliabilitasnya terlebih dahulu. Data yang terkumpul diolah dengan mencari skor rata-rata dan tingkat capaian rata-rata (TCR). Hasil penelitian menunjukkan bahwa secara umum menurut siswa akreditasi Sekolah Menengah Kejuruan (SMK) Negeri 1 Lubuk Sikaping baru pada kriteria sesuai (belum sangat sesuai) antara peringkat yang diperoleh dengan kenyataan yang ada, dengan TCR 81,18\%. Namun jika diamati per aspek yang diukur, maka ada satu aspek, yaitu sarana dan prasarana, yang akreditasinya menurut siswa belum begitu sesuai atau kurang sesuai antara peringkat yang diperoleh dengan kenyataan yang ada, dengan TCR 79,33.
\end{abstract}

Kata Kunci: Persepsi Siswa ; Akreditasi Sekolah

How to Cite: Sarmila, Eci dan Nurhizrah Gistituati. 2021. Akreditasi Sekolah Menurut Persepsi Siswa : Studi di Sekolah Menengah Kejuruan (SMK) Negeri 1 Lubuk Sikaping. Journal of Educational Administration and Leadership, Vol (N): pp. XX-XX, DOI: doi.org/10.24036/jeal.v2i1

\section{Pendahuluan}

Salah satu cara untuk meningkatkan kualitas sumber daya manusia adalah melalui pendidikan. Semakin berkualitas suatu pendidikan maka ouput yang dihasilkan juga semakin berkualitas. Untuk mengetahui pendidikan yang berkualitas salah satunya dapat dilihat dari akreditasi sekolah. Berdasarkan Undang-Undang 
Nomor 20 Tahun 2003 Pasal 60 Ayat 1 dijelaskan bahwa akreditasi dilakukan untuk menentukan kelayakan program satuan pendidikan pada jalur pendidikan formal dan non formal pada setiap jenjang pendidikan. Akreditasi sekolah adalah kegiatan membandingkan kondisi sekolah/madrasah dengan kenyataan sesuai dengan standar yang telah ditetapkan oleh Badan Akreditasi Sekolah (BASNAS). Menurut (Kartono, 2009) akreditasi sekolah merupakan mekanisme penjaminan mutu sekolah yang dilakukan oleh pihak eksternal dengan cara mengevaluasi kinerja setiap lembaga yang terkait dalam sistem penjaminan mutu pendidikan, yang terdiri dari Sekolah, Lembaga Penjaminan Mutu Pendidikan (LPMP), Pemerintah Daerah, dan Pemerintah Pusat. Akreditasi sekolah merupakan kegiatan penilaian kelayakan dan kinerja sekolah berdasarkan pada kriteria atau (standar) yang sudah ditetapkan dan dilakukan oleh Badan Akreditasi Sekolah serta hasilnya diwujudkan berupa pengakuan peringkat kelayakan.

Akreditasi sangat penting bagi kepala sekolah, guru, peserta didik, pemerintah dan para ahli pembuat kebijakan. Bagi kepala sekolah, hasil akreditasi dijadikan sebagai patokan dan sumber informasi dalam pemetaan indikator kelayakan dan kinerja warga sekolah. Bagi guru, akreditasi diharapkan dapat memberikan motivasi untuk meningkatkan kompetensi diri dan memberikan pelayanan yang semaksimal mungkin kepada siswa agar dapat meningkatkan mutu sekolah. Bagi siswa akreditasi sekolah mampu meningkatkan rasa percaya diri serta dengan peringkat akreditasi mereka yakin akan memperoleh pendidikan yang berkualitas sesuai dengan harapannya, dan sertifikat hasil akreditasi menjadi jaminan bahwa siswa peserta didik tersebut memperoleh pendidikan yang bermutu. Bagi masyarakat, terutama bagi orang tua hasil akreditasi dapat memberikan informasi terhadap layanan yang ditawarkan oleh pihak sekolah/madrasah dan secara tidak langsung memberikan rekomendasi kepada masyarakat bahwa sekolah tersebut dianggap layak untuk melakukan proses pembelajaran. Sementara bagi para ahli dan pembuat keputusan hasil akreditasi dapat dianalisis dan memberikan solusi terhadap permasalahan yang sedang dihadapi sekolah tersebut, agar dilakukannya pembinaan dan pengembangan secara kontekstual dan tepat sasaran terhadap sekolah tersebut.

Berdasarkan uraian diatas dapat diketahui bahwa akreditasi sekolah sangat penting bagi lembaga pendidikan karena dengan adanya akreditasi berarti sekolah tersebut mendapat kategori sudah baik, berkualitas, bermutu serta sesuai dengan yang diharapkan dan secara langsung akan mendapatkan pengakuan dari masyarakat akan akreditasi yang diperoleh sekolah tersebut.

Disamping itu akreditasi sekolah seharusnya sesuai antara peringkat akreditasi sekolah yang diperoleh dengan kenyataan yang ada. Namun dalam kenyataannya masih banyak sekolah-sekolah yang peringkat akreditasinya yang kurang sesuai dengan kenyataan yang ada. Sekolah yang mempunyai status akreditasi A seringkali tidak menggambarkan kualitas dari peringkat akreditasi sekolah tersebut, baik itu proses pembelajarannya, aspek pendidik dan tenaga kependidikannya, kompetensi lulusannya, serta sarana dan prasarana yang tersedia. Secara negatif akreditasi dapat diartikan sebagai suatu formalitas yang harus dijalankan institusi lembaga pendidikan demi mendapatkan sebuah peringkat kelayakan. Berdasarkan penelitian yang dilakukan oleh (Irawan, Tagela, \& Windrawanto, 2020) menyebutkan bahwa dilakukannya akreditasi hanya sebatas kegiatan administratif saja. Peringkat akreditasi sekolah idealnya sangat berkaitan erat dengan pencapaian sekolah, namun hasil yang ditemukan dilapangan bahwa belum semua aspek menunjukkan keterkaitan. Sama halnya dengan penelitian yang dilakukan oleh (Kartono, 2009) mengatakan kesan dari pengalaman pelaksanaan akreditasi yang dilakukan sebelumnya yakni akreditasi hanya sebatas kegiatan administrasi belaka. Sementara itu dalam hasil penelitian (Khusnah, 2013) mengungkapkan bahwa semenjak adanya manipulasi data hasil akreditasi diragukan kebenarannya, serta fungsi dan tujuan dari pelaksanaan akreditasi sekolah tidak tercapai dengan semestinya. Tujuan akhir dari akreditasi hanya sebatas menerapkan peraturan dan bukan sebagai cara untuk memperbaiki atau meningkatkan kualitas pendidikan (Akhter \& Ibrahim, 2016).

Berdasarkan hasil pengamatan penulis selama praktek lapangan kependidikan di SMKN 1 Lubuk Sikaping memperlihatkan adanya fenomena yang kurang sesuai antara peringkat Akreditasi yang diperoleh dengan kenyataan yang ada. Hal ini terlihat dari fenomena yang terjadi : a) masih banyak guru-guru yang kurang menguasai teknologi pembelajaran, seperti tidak tahu dan bertanya-tanya bagaimana cara menggunakan aplikasi pembelajaran online (google form, google classroom, zoom dll), b) cukup banyak guru yang belum memahami tentang pembelajaran COE (Center Of Excellence), sehingga saat diberikan sosialisasi banyak guru yang kebingungan, c) buku-buku di perpustakaan terlihat berserakan, tidak ditata sebagaimana mestinya, d) perilaku siswa yang kurang menghargai guru, seperti bercanda saat guru menyampaikan materi, e) keluhan siswa tentang cara mengajar guru, dan juga tentang fasilitas sekolah yang ada, f) terbatasnya sarana sekolah seperti meja dan kursi di ruang guru, di mana ada beberapa orang guru yang tidak memperoleh meja dan kursi kerja sendiri dalam ruang kantor guru, sehingga beberapa orang guru harus duduk berdempetan dengan guru lain.

Akreditasi sekolah dinyatakan sesuai antara hasil dengan kenyataan yang ada apabila tidak ada manipulasi data. Berdasarkan uraian diatas maka penulis tertarik untuk melakukan penelitian mengenai kesesuaian antara peringkat akreditasi sekolah Sekolah Menengah Kejuruan (SMK) Negeri 1 Lubuk Sikaping yang diperoleh dengan kenyataan yang ada. Kesesuaian ini dilihat menurut pendapat siswa. Adapun penelitian ini bertujuan 
untuk mendapatkan informasi tentang 1) Seberapa sesuainya menurut persepsi siswa antara hasil akreditasi sekolah dengan kenyataan yang ada di SMKN 1 Lubuk Sikaping yang berhubungan dengan pelaksanaan pembelajaran?, 2) Seberapa sesuainya menurut persepsi siswa antara hasil akreditasi sekolah dengan kenyataan yang ada di SMKN 1 Lubuk Sikaping yang berhubungan dengan kualitas kompetensi lulusan? 3) Seberapa sesuainya menurut persepsi siswa antara hasil akreditasi sekolah kenyataan yang ada di SMKN 1 Lubuk Sikaping yang berhubungan dengan kualitas pendidik dan tenaga kependidikan? 4) Seberapa sesuainya menurut persepsi siswa antara hasil akreditasi sekolah dengan kenyataan yang ada di SMKN 1 Lubuk Sikaping yang berhubungan dengan sarana dan prasarana yang tersedia?

\section{Metode Penelitian}

Jenis penelitian ini yaitu deskriptif kuantitatif. Menurut Arikunto (2014) penelitian deskriptif yaitu penelitian yang menyelidiki suatu keadaan, dan hasilnya diuraikan dalam laporan penelitian. Sementara itu menurut Castellan (2010) metode penelitian kuantitatif yaitu penelitian yang datanya menggunakan data kuantitatif sehingga datanya dianalisis dengan kuantitatif. Sedangkan menurut Lehmann dalam (Yusuf, 2014) penelitian deskriptif kuantitatif adalah jenis penelitian yang dimaksud untuk mendeskripsikan secara sistematis, faktual, dan akurat mengenai fakta dan sifat populasi tertentu, dan menggambarkan fenomena dengan jelas. Tujuan penelitian ini untuk mengetahui seberapa sesuainya antara hasil akreditasi dengan kenyataan yang ada menurut persepsi siswa. Populasi penelitian ini yaitu siswa kelas XI di SMKN 1 Lubuk Sikaping yang berjumlah 480, dengan besar sampel 90 orang yang ditentukan dengan menggunakan rumus Slovin. Pengambilan sampel menggunakan teknik proportional insidentil sampling. Instrumen penelitian yang digunakan berupa kuesioner model Skala Likert. Sebelum digunakan, kuesioner tersebut diuji validitas dan reliabilitasnya terlebih dahulu. Data yang sudah terkumpul diolah dengan mencari skor rata-rata dan tingkat capaian rata-rata (TCR).

\section{Hasil dan Pembahasan}

\subsection{Hasil}

Secara umum penelitian ini menunjukkan akreditasi sekolah menurut persepsi siswa antara hasil akreditasi dengan kenyataan yang ada di Sekolah Menengah Kejuruan (SMK) 1 Lubuk Sikaping. Terdapat empat indikator digunakan untuk mengukur kesesuaian tersebut, yaitu standar proses, standar kompetensi lulusan, standar pendidik dan tenaga kependidikan dan standar sarana dan prasarana. Hasil olahan data penelitian dapat dilihat pada Tabel 1.

Table 1. Skor Rata-Rata dan TCR Tentang Akreditasi Sekolah Menurut Persepsi Siswa di SMKN 1 Lubuk Sikaping

\begin{tabular}{|c|c|c|c|c|}
\hline \multicolumn{5}{|c|}{ Menurut Persepsi Siswa di SMKN 1 Lubuk Sikaping } \\
\hline \multirow{2}{*}{ No } & \multirow{2}{*}{ Aspek yang diteliti } & \multirow{2}{*}{$\begin{array}{c}\text { Skor } \\
\text { rata-rata }\end{array}$} & TCR & \multirow{2}{*}{ Kriteria } \\
\hline & & & $(\%)$ & \\
\hline 1. & Standar Proses & 4,13 & 81,08 & Sesuai \\
\hline 2. & Standar Kompetensi Lulusan & 4,26 & 84,2 & Sesuai \\
\hline 3. & $\begin{array}{l}\text { Standar Pendidik dan Tenaga } \\
\text { Kependidikan }\end{array}$ & 4,05 & 80,09 & Sesuai \\
\hline 4. & Standar Sarana dan Prasarana & 4,02 & 79,33 & $\begin{array}{l}\text { Kurang } \\
\text { Sesuai }\end{array}$ \\
\hline & Rata-rata & 4,11 & 81,18 & Sesuai \\
\hline
\end{tabular}

Tabel 1 di atas menunjukkan bahwa akreditasi sekolah menurut persepsi siswa di SMKN 1 Lubuk Sikaping baru pada kriteria sesuai (belum sangat sesuai) antara peringkat yang diperoleh dengan kenyataan yang ada dengan skor rata-rata dan TCR 4,11 dan 81,18\%. Jika dilihat per indikatornya maka ada satu indikator yaitu aspek Standar Sarana dan Prasarana yang menurut siswa belum begitu sesuai atau kurang sesuai antara hasil akreditasi dengan kenyataan yang ada dengan skor rata-rata dan TCR 4,02 dan 79,33\%. Namun secara keseluruhan skor rata-rata Akreditasi Sekolah Menurut Persepsi Siswa di SMKN 1 Lubuk Sikaping sudah dinyatakan sesuai. 
Hasil penelitian menunjukkan bahwa akreditasi sekolah menurut persepsi siswa tentang standar proses di SMKN 1 Lubuk Sikaping dengan memperoleh skor rata-rata 4,13 dan TCR 81,08 \% yang sudah berada pada kategori sesuai. Ini terlihat dari perencanaan pembelajaran, pelaksanaan pembelajaran, penilaian hasil dan proses pembelajaran dan pengawasan proses pembelajaran. Dalam aspek ini terdapat 7 item, item yang paling tinggi "Guru memeriksa hasil ujian siswa dengan baik" dengan tingkat capaian $85,11 \%$ berada pada kategori sesuai. Kemudian item yang paling rendah yaitu "Guru menggunakan media yang bervariasi dalam melaksanakan pembelajaran untuk meningkatkan minat siswa" dengan tingkat capaian 70,22\% berada pada kategori kurang sesuai. Kemungkinan penyebab rendahnya rata-rata tingkat capaian pada item "Guru menggunakan metode pembelajaran bervariasi dalam melaksanakan pembelajaran untuk meningkatkan siswa" karena kurangnya media pendukung kreativitas guru untuk melaksanakan pembelajaran, dan ketika pembelajaran berlangsung guru lebih dominan menggunakan metode ceramah. Hal ini menunjukkan perlunya peningkatan pada aspek standar proses yang saat ini berada di kategori sesuai agar dapat menjadi kategori sangat sesuai. Jadi untuk meningkatkan aspek standar proses menjadi kategori sangat sesuai guru dan harus memperhatikan proses pembelajaran di sekolah agar siswa meningkatkan semangat belajar dan tercapainya tujuan pendidikan.

Hasil penelitian menunjukkan bahwa akreditasi sekolah menurut persepsi siswa tentang standar kompetensi lulusan di SMKN 1 Lubuk Sikaping dengan memperoleh skor rata-rata 4,26 dan TCR 84,2\% yang berada pada kategori sesua. Ini terlihat dari dari aspek sikap, pengetahuan dan keterampilan. Dalam aspek ini terdapat 12 item, item yang paling tinggi yaitu "Siswa berperilaku sesuai dengan aturan agama yang dianut" dengan tingkat capaian $86,22 \%$ berada pada kategori sesuai. Kemudian item yang paling rendah adalah "Siswa menguasai kompetensi program keahlian untuk memenuhi tuntutan perguruan tinggi sesuai dengan kejuruan" dengan tingkat capaian $82 \%$ berada pada kategori sesuai. Kemungkinan penyebab rendahnya rata-rata tingkat capaian pada item "Siswa menguasai kompetensi program keahlian untuk memenuhi tuntutan perguruan tinggi sesuai dengan kejuruan" tersebut karena siswa SMKN 1 Lubuk Sikaping memiliki kompetensi sesuai dengan bidangnya sehingga mereka siap untuk melanjutkan ke dunia kerja dan minat siswa masih belum begitu tinggi untuk melanjutkan pendidikan ke perguruan tinggi.

Hasil penelitian menunjukkan bahwa akreditasi sekolah menurut persepsi siswa tentang standar pendidik dan tenaga kependidikan di SMKN 1 Lubuk Sikaping dengan memperoleh skor rata-rata 4,05 dan TCR 80,09\% berada pada kategori sesuai. Hal ini terlihat dari aspek kepala sekolah, guru, tenaga administrasi, tenaga perpustakaan, dan tenaga laboratorium. Dalam aspek ini terdapat 10 item, item yang paling tinggi yaitu "Kepala sekolah memiliki kemampuan yang baik untuk bekerjasama dengan pihak lain guna kepentingan sekolah" dengan tingkat capaian $86,67 \%$ berada pada kategori sesuai. Kemudian item yang paling rendah yaitu "Tenaga perpustakaan sekolah memiliki kemampuan dalam mengelola perpustakaan" dengan tingkat capaian 66\% berada pada kategori kurang sesuai. Kemungkinan penyebab rendahnya rata-rata tingkat capaian pada item "Tenaga perpustakaan sekolah memiliki kemampuan dalam mengelola perpustakaan" tersebut karena kurangnya pelatihan atau pemahaman yang dimiliki oleh pengelola perpustakaan. Menurut (Armaiyetti, Marsidin, \& Alkadri, 2020) pendidik dan tenaga kependiidkan adalah salah satu komponen yang paling penting untuk menunjang proses pembelajaran diksekolah. Hal ini menunjukkan perlunya peningkatan pada aspek pendidik dan tenaga kependidikan khususnya terhadap tenaga perpustakaan sekolah yang saat ini berada di kategori kurang sesuai agar dapat menjadi kategori sesuai atau sangat sesuai.

Selanjutnya hasil penelitian menunjukkan bahwa akreditasi sekolah menurut persepsi siswa tentang standar sarana dan prasarana di SMKN 1 Lubuk Sikaping dengan memperoleh skor rata-rata 4,02 dan TCR 79,33\% pada kategori kurang sesuai. Hal ini dapat dilihat dari aspek ruang kelas, ruang perpustakaan, ruang, ruang laboratorium komputer, ruang guru, ruang tata usaha dan tempat ibadah. Dalam aspek ini terdapat 7 item, item yang paling tinggi adalah "Di ruang kelas siswa melihat masih banyak meja yang kurang layak dipakai" dengan tingkat capaian $84,89 \%$ berada pada kategori sesuai. Kemudian item yang paling rendah yaitu "Siswa merasa kurang nyaman saat melakukan ibadah karena tempat ibadah yang sempit" yaitu memperoleh tingkat capaian 65,56\% pada kategori kurang sesuai. Menurut Megasari (2014) pihak sekolah seharusnya memperhatikan dan memelihara sarana dan prasarana yang tersedia disekolah. Menurut Sementara berdasarkan penelitian yang telah dilakukan oleh (Fitri, Syahril, Ermita, \& Irsyad, 2020) pelaksanaan shalat dilakukan secara bergantian dikarenakan tempat ibadah yang kecil dan sempit. Kemungkinan penyebab rendahnya ratarata tingkat capaian pada item "Siswa merasa kurang nyaman saat melakukan ibadah karena tempat ibadah yang sempit" tersebut karena lokasi untuk tempat ibadah yang sangat minim dan terbatas. Hal ini menunjukkan perlunya peningkatan pada aspek standar sarana dan prasarana yang saat ini berada di kategori kurang sesuai agar dapat menjadi kategori sesuai. 


\section{Simpulan}

Berdasarkan hasil penelitian yang telah diuraikan diatas mengenai akreditasi sekolah menurut persepi siswa di SMKN 1 Lubuk Sikaping dapat ditarik kesimpulan : standar proses berada pada kategori sesuai dengan memperoleh tingkat capaian 81,08\%, standar kompetensi lulusan di SMKN 1 Lubuk Sikaping menurut persepsi siswa berada pada kategori sesuai dengan memperoleh tingkat capaian $84,2 \%$, standar pendidik dan tenaga kependidikan di SMKN 1 Lubuk Sikaping menurut persepsi siswa berada pada kategori sesuai dengan memperoleh tingkat capaian 80,09\%, dan standar sarana dan prasarana di SMKN 1 Lubuk Sikaping menurut persepsi siswa berada pada kategori kurang sesuai dengan memperoleh tingkat capaian 79,33\%. Berdasarkan kesimpulan diatas, maka penulis mengemukakan beberapa saran sebagai berikut : a) untuk guru diharapkan untuk lebih memperhatikan dan meningkatkan kualitas mengajar dikelas, agar pembelajaran tidak hanya menjadi rutinitas tetapi untuk mencapai hasil yang optimal sehingga sesuai dengan harapan, b) untuk siswa diharapkan agar lebih memperhatikan aspek-aspek dalam standar kompetensi lulusan dan menjalankannya dengan baik agar menghasilkan lulusan yang baik yang berkompeten di bidangnya, c) bagi pendidik dan tenaga kependidikan diharapkan untuk lebih maksimal dalam melakukan tugas dan memiliki sikap bertanggung jawab agar standar tenaga pendidik dan kependidikan lebih baik lagi, d) dan bagi kepala sekolah dan semua pihak sekolah diharapkan agar memperhatikan ketersediaan sarana dan prasarana agar proses pembelajaran tidak terkendala karena kurangnya sarana dan parasana di sekolah.

\section{Daftar Rujukan}

Akhter, F., \& Ibrahim, Y. (2016). Intelligent Accreditation System: A Survey of the Issues, Challenges, and Solution. International Journal of Advanced Computer Science and Applications, 7(1), 477-484. https://doi.org/10.14569/ijacsa.2016.070165

Arikunto, S. (2014). Prosedur Penelitian Suatu Pendekatan Praktik. Jakarta: Rineka Cipta.

Armaiyetti, R., Marsidin, S., \& Alkadri, H. (2020). Pengaruh Kepemimpinan Kelapa Sekolah dan Dana Bos terhadap Prestasi Guru. Jurnal Basicedu, 4(2), 453-459. https://doi.org/10.31004/basicedu.v4i2.380

Castellan, C. M. (2010). Quantitative and Qualitative, Quantitatif Research: A View for Clarity. In International Journal of Education (Vol. 2, p. 2). Las Vegas: Macrothink Institute.

Fitri, S. I., Syahril, Ermita, \& Irsyad. (2020). Profil Sekolah Menengah Pertama Negeri Se- Kecamatan Sangir Jujuan Ditinjau Berdasarkan Standar Prasarana. Journal Of Educational And Leadership (JEAL), 1(3), 6268.

Irawan, S., Tagela, U., \& Windrawanto, Y. (2020). Hubungan Akreditasi Sekolah dan Supervisi oleh Kepala Sekolah dengan Kualitas Sekolah, 8(2), 165-174.

Kartono. (2009). Sekolah Bukan Pasar: Catatan Otokriti Seorang Guru. Jakarta: Kompas.

Khusnah, L. (2013). Akreditasi Sekolah antara Harapan dan Kenyataan. Bioshell, 2(1), 58-91.

Megasari, R. (2014). Peningkatakan Pengelolaan Sarana dan Prasarana Pendidikan Untuk Meningkatkan Kualitas Pembelajaran di SMPN 5 Bukittinggi. Jurnal Bahana Manajemen Pendidikan, 2(1), 636-831. https://doi.org/10.24042/alidarah.v8i1.3088

Yusuf, M. (2014). Metode Penelitian Kuantitatif, Kualitatif \& penelitian Gabungan. Jakarta: Prenada Group. 